\title{
Mapeamento e panorama dos frigoríficos de bovinos do estado de Santa Catarina
}

\author{
Diego de Córdova Cucco', Bruno Barzotto Abdalla², Fernanda Rigon², Maisa Chiocca², Jonathan Sá2, Gabriel Zieher², \\ Vinícius Paulo Agostini² e Aline Zampar ${ }^{3}$
}

\begin{abstract}
Resumo - No Brasil geralmente não ocorre uma ligação entre os setores da cadeia produtiva de bovinos de corte, como produtores, frigoríficos e consumidores. Há escassez de informações a respeito do perfil do gado abatido e da demanda do mercado, o que acaba por não ser identificada a real situação da cadeia. O objetivo do trabalho foi mapear os frigoríficos de maior relevância em Santa Catarina registrados nos serviços de inspeção federal, estadual e municipal e pesquisar junto a eles a situação dos abates, suas demandas e anseios. As informações coletadas dizem respeito ao perfil das unidades, às características dos animais abatidos, às demandas das empresas e suas preocupações e perspectivas. Após coleta e análise dos dados, ficou claro que os estabelecimentos não alcançam a capacidade total de abate diário e abatem animais com qualidade inferior à desejada, com pouco acabamento de gordura e em alguns casos de aptidão leiteira, pela falta de oferta. Foi possível conhecer e compreender melhor este elo da cadeia, com isso pode-se auxiliar pecuaristas a direcionar a produção para atender as demandas exigidas pelo mercado.
\end{abstract}

Termos para indexação: Abate; Carne bovina; Pecuária de corte; Produção animal.

\section{Mapping and panorama of cattle slaughterhouses in Santa Catarina State}

\begin{abstract}
Generally, in Brazil there is no connection between sectors of the beef cattle production chain, such as producers, slaughterhouses and consumers. There is a lack of information about the profile of slaughtered cattle and market's demand, which ends up not being identified the real situation of the chain. The objective of this study was to map the most relevant slaughterhouses in Santa Catarina registered with the federal, state and municipal inspection services and research the slaughter situation with them, your demands and desires. After collection and data analysis, it was clear that the establishments do not reach full daily slaughter capacity and slaughter animals of less than desired quality, with scarce finish and in some cases dairy cattle, for lack of supply. It was possible to know and better understand this link in the chain, with that we can orientate farmers production to meet the market's demands.
\end{abstract}

Index-terms: Animal production; Beef cattle; Meat; Slaughter.

O Brasil é caracterizado pela sua diversidade na produção animal, reconhecido por ter um grande potencial de produção e por possuir área suficiente para tal. Na criação de bovinos de corte, tem-se um sistema produtivo característico em cada região, porém há pouca integração entre os setores da cadeia produtiva, como produtores, frigoríficos e consumidores. Em Santa Catarina há um déficit de carne bovina para consumo interno. Em 2014 a disponibilidade de carne bovina no Estado foi de 290,8 mil toneladas e cerca de $48,60 \%$ dela foi adquirida de outros estados e países (CEPA, 2015).

Existem poucos estudos no país, e ainda menos no Estado, referentes à cadeia produtiva de bovinos, sobre o que é abatido, o tipo de animal fornecido e desejado pelos frigoríficos e pelo consumidor. Muitas vezes o pecuarista pode não ofertar a carne conforme a demanda, pois desconhece as exigências do mercado. De acordo com Barcellos et al. (2011), o pecuarista deve descobrir o que o seu cliente (frigorífico ou consumidor) deseja, pois, quando o comprador identifica o diferencial do produto, a remuneração ao produtor poderá ser maior.

O objetivo deste trabalho foi mapear os frigoríficos de bovinos com maior volume de abates no Estado e pesquisar junto a eles a situação dos abates, para realizar um panorama da produção das unidades, conhecer os principais entraves nesse processo e as perspectivas futuras para o setor.

Foi realizado o levantamento dos principais frigoríficos de bovinos no Estado de Santa Catarina com registro no Serviço de Inspeção Federal (S.I.F.), Inspeção Estadual (S.I.E.) e Inspeção Municipal (S.I.M.), por meio de contato e solicitação de dados junto aos órgãos responsáveis: Ministério da Agricultura Pecuária e Abastecimento (Mapa), a Companhia Integrada de Desenvolvimento Agrícola de Santa Catarina (Cidasc) e Secretarias de Agricultura Municipais. Com estas unidades identificadas e sua localização geográfica cadastrada, foram contatados inicialmente trinta

2 Zootecnistas, formados (as) pela Universidade do Estado de Santa Catarina - Udesc/Centro de Educação Superior do Oeste, C.P. 89815-630 Chapecó, SC, e-mail: b.abdalla@hotmail.com; fe.rigon@hotmail.com; maisachiocca@hotmail.com; jonathan-agro@hotmail.com; gabriel-zieher@gmail.com; agosti ni_ vinicius@hotmail.com;

${ }^{3}$ Zootecnista, Dra., Professora Adjunta do Departamento de Zootecnia Universidade do Estado de Santa Catarina - Udesc, C.P. 89815-630 Chapecó, SC, fone (49) 20499553, e-mail: aline.zampar@udesc.br. 
frigoríficos distribuídos por toda extensão estadual, dentre os quais foram selecionados os dez estabelecimentos com os maiores volumes de abates.

A pesquisa teve como finalidade obter informações gerais sobre os estabelecimentos, como: tipo de registro de inspeção, espécies abatidas, capacidade e frequência de abate, lote mínimo para compra de animais e regiões de procedência dos bovinos. Também foram coletados os dados dos animais abatidos, como o tipo animal (corte, leite, aptidão mista), idade, raça, classe sexual, peso vivo médio, rendimento de carcaça, acabamento de carcaça.

Foram realizados questionamentos sobre os dados de mercado, em relação ao destino dos miúdos, ao mercado atendido pela empresa, à realização de parcerias de compra e venda e aos programas de bonificação e penalização. Informações sobre os principais entraves e perspectivas futuras também foram questionadas. Os dados obtidos foram tabulados e analisados de forma descritiva.

Das dez empresas relevantes focadas neste estudo $60 \%$ são submetidas à inspeção estadual e $40 \%$ à federal. Cabe ressaltar que a inspeção estadual abrange o fornecimento apenas para o Estado, enquanto a federal possibilita a comercialização nacional.

Todos os estabelecimentos relataram que não conseguem abater a sua capacidade máxima diária, pela falta de oferta de animais. Isto faz com que alguns estabelecimentos realizem a compra de carcaças bovinas de outros estados brasileiros para conseguir atender a demanda dos mercados locais e otimizar sua mão de obra.

Em geral, os frigoríficos de maior porte realizam o abate diário. Frigoríficos de menor porte realizam abates em dias alternados. Neste estudo, não foi encontrada relação entre o número de cabeças abatidas pelo estabelecimento e a frequência de abate. Tanto os estabelecimentos de grande ou menor porte alternam entre as diferentes frequências de abates, sendo $50 \%$ abate diário e $50 \%$ dias alternados.

Em relação aos dados de compra, $70 \%$ não possuem quantidade mínima estabelecida para a aquisição de animais. Este fato pode ser explicado pela baixa oferta de animais para abate. Desta forma, o frigorífico não pode exigir um lote mínimo ao fornecedor, uma vez que pode ficar sem animais para o abate.

Grande parte dos estabelecimentos adquire animais das Mesorregiões Oeste e Serrana do Estado. No entanto, nota-se que a distância entre os frigoríficos e as propriedades varia de 100 a $700 \mathrm{~km}$, abrangendo praticamente toda a extensão catarinense.

A idade média dos bovinos abatidos variou de 1,5 a 4 anos, porém alguns estabelecimentos relataram o abate rotineiro de animais de descarte com idade mais avançada. A maioria dos estabelecimentos (70\%) relata abater animais jovens (até 30 meses). Em contrapartida, 30\% dos frigoríficos descreveram uma média de idade de abate superior.

Quanto à aptidão os animais de corte compõem $48 \%$ dos abates, $26 \%$ são de dupla aptidão (corte/leite) e o restante exclusivamente tipo leite (26\%). Esse dado se justifica porque o Estado tem como característica a produção leiteira, principalmente na região Oeste, a qual é responsável por $67 \%$ da produção de leite estadual (SEAP, 2018). Nos abates a raça prevalente é a Charolês, bastante difundida em Santa Catarina. Os estabelecimentos relataram variações conforme a região do Estado, com maior prevalência de animais zebuínos na região Litorânea, animais taurinos na Serrana e grande predominância de animais com aptidão leiteira no Oeste.

Em relação ao sexo dos animais $40 \%$ dos estabelecimentos abatem na mesma proporção machos e fêmeas, outros $40 \%$ maior porcentagem de machos e apenas $20 \%$ maior número de fêmeas. Sobre os machos, foram questionados em relação à porcentagem de animais castrados ou não. A maioria (60\%) abate igual proporção, outros $40 \%$ possuíam porcentagens bem distintas.

O peso vivo médio dos animais abatidos entre todos os estabelecimentos foi de $457 \mathrm{~kg}$. Vale destacar que $30 \%$ dos estabelecimentos realizam a pesagem ainda a campo, os demais estabelecimentos realizavam a pesagem préabate ou a pesagem da carcaça. Para o rendimento de carcaça, foram observados valores de $45 \%$ até $54 \%$, com uma média de rendimento em 51\% (Tabela 1).

Quanto ao acabamento médio de carcaça, relataram abater animais entre $1 \mathrm{~mm}$ à $10 \mathrm{~mm}$ de espessura de gordura, equivalente ao nível 2 a 4, conforme o sistema nacional de tipificação (BRASIL, 1986). Sessenta por cento dos frigoríficos afirmou abater animais com um acabamento médio de carcaça entre 3 e $6 \mathrm{~mm}$ e $30 \%$ entre 1 e $3 \mathrm{~mm}$, ou seja, neste último caso possuíam um acabamento inferior ao desejado na sua maioria, o que pode prejudicar a qualidade da carne produzida por haver insuficiente cobertura de gordura para proteger a carcaça no momento do resfriamento. Isto possivelmente justifica o fato de quatro frigoríficos possuírem confinamento próprio, com o intuito de impor ou melhorar o acabamento dos animais.

Com relação aos miúdos (sangue, sebo, ossos e vísceras) estes eram vendidos para fabricação de farinha, em alguns casos destinados à graxaria, o couro destinado a curtumes, sem agregar valor aos produtos. Apenas uma planta explorava a exportação dos miúdos para mercados como a Ásia, o Oriente Médio e África.

O mercado atendido e o destino final da carne são dependentes do tipo

Tabela 1. Características relevantes observadas e esperadas dos bovinos abatidos pelos principais frigoríficos catarinenses

Table 1. Relevant observed and expected characteristics of cattle slaughtered by the main slaughterhouses in Santa Catarina

\begin{tabular}{|ccc|}
\hline Características & Observado & Perspectiva \\
\hline Idade de abate (meses) & 33 & 25 \\
\hline Abate de machos (\%) & 1 & 50 \\
\hline Peso de abate $(\mathrm{kg})$ & 40 & 505 \\
\hline Abate de raças tipo corte (\%) & 457 & 60 \\
\hline Rendimento de carcaça (\%) & 48 & $50-54$ \\
\hline Parcerias para comercialização $(\%)^{1}$ & 51 & 100 \\
\hline Porcentagem de estabelecimentos. & 80 & \\
\hline
\end{tabular}


de inspeção. Ficou evidente que os estabelecimentos não exploravam a exportação. O que pode ser explicado, pois não há um volume de carne suficiente para suprir o mercado estadual e muito menos o externo.

As parcerias de compra de animais ainda são pouco utilizadas pelos estabelecimentos, o que demonstra um mercado que pode ser explorado. Em relação às parcerias de venda, $80 \%$ das empresas realizavam a venda da carne com supermercados, restaurantes e hotéis. Outra parceria realizada é com organizadores de festas locais, para quem nas datas festivas havia venda de carne em grandes quantidades com um preço mais acessível ao varejo.

Cerca de $60 \%$ dos estabelecimentos possuíam algum tipo de programa de bonificação, como por idade ou acabamento de carcaça. Paralelo a isso, $20 \%$ dos estabelecimentos relataram a existência de algum tipo de penalização, geralmente atrelada a animais com aptidão leiteira, animais sem acabamento desejado e/ou lesionados.

A baixa oferta de animais foi relatada como problema por $80 \%$ dos estabelecimentos. Quando ocorre a oferta de animais para abate, $40 \%$ relataram que não atingem o volume adequado para logística, que seria a carga completa para um caminhão de dois eixos, de acordo com alguns estabelecimentos.

A falta de padronização/uniformidade dos animais abatidos foi citada por $70 \%$. Outros entraves citados foram o mau acabamento escasso de carcaça e o peso de abate, pois alguns produtores ainda destinavam animais com peso abaixo do desejado (animais magros) ou acima do desejado (animais excessivamente gordos), sendo esse último menos frequente.

A idade dos animais que os estabelecimentos pretendem abater é de 25 meses, com no máximo 30, caracterizado como novilho precoce, porém $50 \%$ deles têm o intuito de abater animais superprecoces.

Cinquenta por cento dos estabelecimentos manifestaram preferência por abater machos em relação a fêmeas, os demais foram indiferentes e disseram que estão apenas preocupados com a qualidade dos animais, independente do sexo, mas nenhum deles deseja abater exclusivamente fêmeas. Aos estabelecimentos que responderam ter como preferência o abate de machos, foi questionado se a preferência é por animais castrados ou não. Destes, 30\% almejam abater machos castrados e 70\% não citaram preferência.

No item peso vivo dos animais, 90\% dos frigoríficos pretendem abater animais com pesos vivos entre 480 e $550 \mathrm{~kg}$, sendo a média das respostas $505 \mathrm{~kg}$, denotando assim tendência do mercado em obter carcaças de maior tamanho/peso.

Quanto à preferência em abater uma raça ou cruzamentos específicos, alguns foram indiferentes (40\%), o restante manifestou interesse em animais com aptidão para produção de carne. Muitos deles têm alta preferência por animais de raças taurinas, sejam de raças puras ou cruzamentos com raças zebuínas.

A maioria (70\%) deseja abater animais com rendimentos de carcaça entre 50 - 54\%, 30\% dos estabelecimentos manifestaram-se mais exigentes, com desejo em abater animais com 55\% de rendimento de carcaça ou mais. $\mathrm{O}$ acabamento médio desejado foi para espessuras entre 3 a $4 \mathrm{~mm}$. Porém, 30\% dos estabelecimentos não manifestaram seus anseios para acabamento, talvez pelo próprio desinteresse para essa característica ou até mesmo o desconhecimento de sua importância.

Todos os estabelecimentos têm interesse em firmar novas parcerias, sejam elas referentes à compra de animais, com os produtores, cooperativas, associações de raça ou para a venda de produtos, com supermercados, restaurantes, hotéis e demais mercados. Desta forma deverá ocorrer uma organização da cadeia no segmento da carne, o que acarretará benefícios aos diversos setores envolvidos. Importante ainda destacar que a grande maioria dos estabelecimentos (80\%) manifestou interesse em expandir a planta de abate.

A produção de cortes especiais é uma alternativa para agregar valor ao produto e divulgação da própria marca do frigorífico, porém requer um maior custo de produção, com mais mão de obra e estrutura específica. Cerca de $60 \%$ dos estabelecimentos possuíam interesse em produzir esse tipo de produto e $40 \%$ não, os quais alegaram possuir outros objetivos.

O tipo animal destinado para o abate está aquém do desejado pelos estabelecimentos, os quais almejam abater animais de aptidão carne, pre- coces e/ou superprecoces, com bom acabamento de gordura e peso ideal de abate, para assim garantir a qualidade do produto entregue aos consumidores. Também foi constatado que alguns estabelecimentos não valorizam as carcaças de qualidade, pois $30 \%$ não têm a devida preocupação com o acabamento de gordura.

Os produtores do Estado devem observar a carência de animais dentro dos padrões requeridos e em volume para assim direcionarem sua produção, bem como observar as tendências de pagamento por qualidade das carcaças.

Este trabalho permitiu compreender de maneira aplicada a cadeia de produção de carne bovina no estado de Santa Catarina, bem como sua situação atual e suas demandas. Este panorama nos permite auxiliar pecuaristas e empresas na produção de uma carne com características desejáveis pelos frigoríficos e adequada ao mercado consumidor.

\section{Agradecimentos}

A todos os frigoríficos que contribuíram de maneira irrestrita para a condução deste estudo.

\section{Referências}

BARCELLOS, J.O.J., OLIVEIRA, T.E., MARQUES, P.R., CANELLAS, L.C., CANOZZI, M.E.A., GOMES, A.T. Bovinocultura de corte: cadeia produtiva \& sistema de produção. Guaíba: Agrolivros, p. 27-29. 2011.

BRASIL. Ministério da Agricultura, Pecuária e Abastecimento. Gabinete do Ministro. Instrução Normativa de № 9 de $\mathbf{4}$ maio de 2004. Sistema de Classificação de Bovinos. Portaria n. 612, de 05 de outubro de 1986. Disponível em: https://www.defesa.agricultura.sp.gov.br/legislacoes/instrucao-normativa-9-de-04-05-2004,643.html. Acesso em: 24 mar. 2021

CEPA Centro de Socioeconomia e Planejamento Agrícola (Org.). Números da agropecuária catarinense. Florianópolis: Epagri/ Cepa, 2015, p. 45. Disponível em: http://docweb.epagri.sc.gov.br/website_cepa/publicacoes/Numeros_agropecuarios_2015.pdf. Acesso em: 27 abr. 2020.

SANTA CATARINA. Secretaria do Estado da Agricultura e da Pesca. InfoAgro. Florianópolis, 2018. Disponível em: http://www.infoagro.sc.gov.br/index.php/safra/producaoanimal-2. Acesso em: 04 jun. 2020. 